\title{
Natural disasters in northwestern China, AD 1270-1949
}

\author{
Harry F. Lee*, David D. Zhang \\ Department of Geography, University of Hong Kong, Pokfulam Road, Hong Kong SAR
}

\begin{abstract}
The long-term dynamic of natural disasters drawn from historical records is vital for predicting the future impacts of such disasters and developing proper countermeasures against them. While many studies have examined historical natural disasters in eastern and southern China, few works published in international journals address past disasters in northwestern China. This study seeks to explore the factors underlying various disasters (drought, flood, hail, frost, dust storms, pests and famine) in the Gan-Ning-Qing Region of northwestern China from AD 1270 to 1949 at a multidecadal scale. Via principal component analysis, we extracted 2 rotated principal components, explaining $53.55 \%$ of the temporal variance of the 7 types of disasters. The first principal component had hail, flood, dust storms and frost loading on it, which positively correlated with population pressure. The second principal component had drought and famine loading on it, which were significantly linked to atmospheric circulation. The remaining variance might be attributable to the independent character of pest disasters and low-frequency temperature forcing. Due to global warming and local geographic context, both expanding population and anomalous atmospheric circulation may increase societal vulnerability to natural disasters in northwestern China.
\end{abstract}

KEY WORDS: Natural disasters $\cdot$ Population pressure $\cdot$ Atmospheric circulation anomalies $\cdot$ Principal component analysis $\cdot$ Semi-arid region $\cdot$ Northwestern China

Resale or republication not permitted without written consent of the publisher

\section{INTRODUCTION}

One of the major concerns about global warming is that it will lead to an increase in extreme weather events. In addition, societal infrastructure is becoming more sensitive to weather and climate extremes, which will be exacerbated by climate change (Easterling et al. 2000). Extreme weather conditions result in more natural disasters and associated economic losses; therefore, the attention of policy makers is turning to questions regarding how people and societies can adapt to the risks posed by climate change and prepare in advance for disasters (Helmer 2006). In this context, scientific studies that examine natural disasters have received special attention in recent years (Barlow et al. 2002, McCabe et al. 2004, Vicente-Serrano \& López-Moreno 2006). However, the time span of these studies often is constrained by the availability of instrumental records, frequently less than $100 \mathrm{yr}$ before the present day, which may be too short to account for the very long-term dynamics of natural disasters (including periods of different climate characteristics). Dynamics at this scale are vital for predicting the future impacts of, and developing proper countermeasures against, natural disasters.

Paleo-climatic proxies (sediment stratigraphy and the species compositions of fossil diatom and midge assemblages) offer the potential to elicit the dynamics of natural disasters within the context of longer term varying climatic conditions (Verschuren et al. 2000, Shanahan et al. 2009). Yet, apart from flood and drought, these proxies have not proved to be effective in reconstructing other disasters.

Historical records turn out to be valuable data sources for the study of the long-term dynamics of various natural disasters. Although historical records may be biased by the perception of different observers, they provide both reliable time scales of and direct 
information about the disasters. Also, their easy availability is an asset (Glaser \& Stangl 2003, Chu et al. 2008).

In China, there are numerous, precisely dated historical documents (including dynastic histories, local chronicles, agricultural records, geographic monographs, personal travelogues, monographs on geography or water conservancy and other archival materials) that contain information about historical natural disasters. Because China is an agrarian country, agriculture was regarded as extremely important during each dynasty, and much attention was paid to natural disasters, especially when the country was stable and flourishing. To prevent inaccurate reports of natural disasters, the records of some dynasties, such as the Qing (ca. AD 1644-1911), were recorded according to several different systems at the same time and were crosschecked (Tan et al. 2008). Therefore, the number and quality of historical Chinese natural disaster records is extremely high and may be unique worldwide, which offers scholars an extraordinary opportunity to investigate various historical natural disasters.

Although much attention has focused on the disasters (flood and drought in particular) in eastern and southern China (Liu et al. 2001, Jiang et al. 2005, 2006, Stige et al. 2007, Chu et al. 2008, Zhang et al. 2008b, 2009, Yin et al. 2009), few studies have carefully considered the disasters in northwestern China. This phenomenon may be attributable to the fact that historical documents are less abundant in northwestern China than in eastern and southern China. Northwestern China is a zone characterized by its ecological fragility and susceptibility to environmental change. As natural disasters have been a limiting factor for the economy and society in northwestern China, their study is not only of academic interest but also of practical value for predicting the consequences of future occurrences (Yuan 1994).

The purpose of the present study was to obtain an overview of various natural disasters in northwestern China and, most importantly, explore the underlying factors which drove trends and fluctuations at the multi-decadal scale over a long period. It should be noted that the above issues will be addressed in a broad sense, with little attention being paid to individual cases.

\section{DATA AND METHODS}

Northwestern China includes the autonomous regions of Xinjiang and Ningxia and the provinces of Sha'anxi, Gansu and Qinghai. The total area of the region is 3.09 million $\mathrm{km}^{2}$, comprising approximately one-third of China's land area. Arid regions occupy a vast area in northwestern China, where the mean annual rainfall is less than $250 \mathrm{~mm}$. Within the region, annual precipitation in the western plains is in the range of 50 to $150 \mathrm{~mm}$, and less than $25 \mathrm{~mm}$ in the Taklimakan Desert. The annual evaporation, however, is more than $1400 \mathrm{~mm}$ on average, and about 2000 to $3000 \mathrm{~mm}$ in the desert areas. Because of the arid climate, only a small portion of the total area in the region is used for farm production $\left(\sim 0.13\right.$ million $\left.\mathrm{km}^{2}\right)$. Irrigated farmlands are located primarily in Ningxia Plain, Hexi Corridor Region in Gansu and the northern oasis area of Xinjiang. In other parts of this region, most of the cultivated area is rain-fed, with scattered irrigated areas (Deng et al. 2005).

It would be a laborious task to sift through the hundreds of voluminous historical documents to extract natural disaster records. Fortunately, a detailed inventory of natural disasters for northwestern China has been compiled and tabulated by Yuan (1994), which provides the data used in the present study. Beyond his original study, this unique data set has until now remained unexplored. In his compilation, Yuan (1994) relied on a careful survey of 685 volumes of various official dynastic histories, local chronicles and instrumental data from local meteorological stations to tabulate 7 types of historical natural disasters (drought, flood, hail, frost, dust storms, pests and famine) for Gansu, Ningxia and eastern Qinghai (the Gan-NingQing Region [GNQR]). This is believed to be one of the most accurate and comprehensive historical natural disaster data sets for northwestern China. Accordingly, our study area was delineated to be the GNQR (Fig. 1). GNQR is located at the eastern side of the Tibetan Plateau and the present-day northern limit of the Asian summer monsoon (Indian summer monsoon and East Asian summer monsoon). The hydrological balance and effective moisture of the region is controlled by the interactions of competing factors, including the Asian summer monsoon, winter monsoon and westerlies (Tan et al. 2008). The region is semi-arid, with annual precipitation less than $500 \mathrm{~mm}, 80 \%$ of which falls between May and September, leaving winter and spring extremely dry (Zhang et al. 2008a).

When dealing with historical data, one has to be aware of the subjective nature of written sources. The reason for this is the fundamental influence of man's individual perception. To separate subjective from objective components of historical sources and to reflect the areal extent of natural disasters, in the Yuan (1994) data set, each type of natural disaster was quantified on a yearly basis by summing up the spatial weightings of the affected regions (Table 1). Special attention should be paid to some cases. If a particular type of natural disaster affected only part of a regionsay the northern part of the Qingyang Region was 


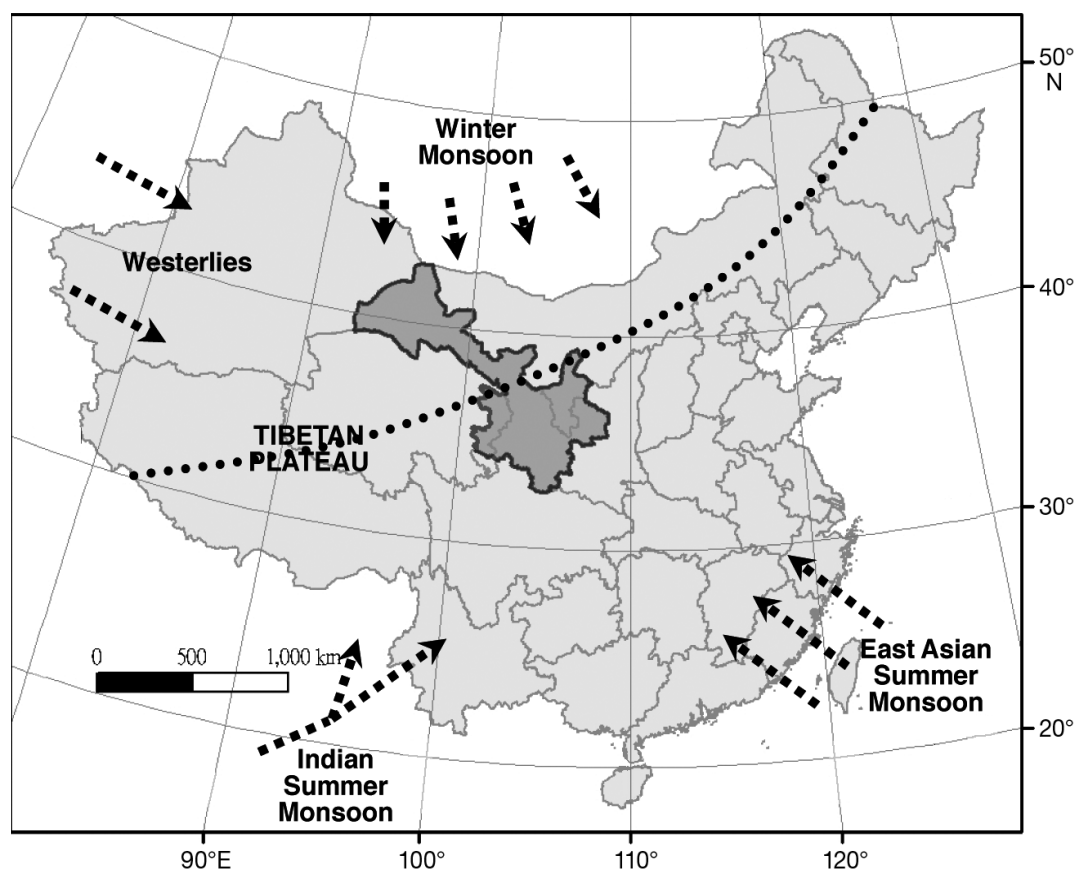

Fig. 1. China. The Gan-Ning-Qing Region (GNQR) is highlighted in dark grey. Arrows represent the Asian summer monsoon (East Asian summer monsoon and Indian summer monsoon), westerlies and winter monsoon. Dotted line illustrates the approximate present-day northern limit of the Asian summer monsoon

Grade 0: Year without flooding

Grade 1: $<10 \%$ of the GNQR was flooded in a year

Grade 2: $11-20 \%$ of the GNQR was flooded in a year

Grade 3: $21-30 \%$ of the GNQR was flooded in a year

Grade $4: 31-50 \%$ of the GNQR was flooded in a year

Grade 5: $>50 \%$ of the GNQR was flooded in a year

Grade 6: Devastating floods

The above procedure was also applied to the other natural disasters in the GNQR for the period from AD 1270 to 1949 . This period of record was chosen for analysis because it is common to the 7 types of natural disaster quantified by Yuan (1994). The resulting time series and grade distribution of the disasters are shown in Fig. 2 and Table 2, respectively.

The time series of natural disasters were subjected to a principal component analysis (PCA) via SPSS for dimension reduction, such that their

flooded - half of the region's weighting would be applied (i.e. $6 \times 0.5=3$ ). If a county in the Qingyang Region was flooded, 1 point would be added to the weighting. Based upon the summation of the spatial weightings, flooding in the GNQR in a particular year was graded as follows:

Table 1. Spatial weighting of various geographic units in the Gan-Ning-Qing Region (GNQR). Each value represents a percentage of the total area in the GNQR

\begin{tabular}{|llc|}
\hline Province & Geographic region & $\begin{array}{c}\text { Spatial } \\
\text { weighting }\end{array}$ \\
\hline Gansu & Qingyang Region & 6 \\
& Pingliang Region & 6 \\
& Tianshui City & 6 \\
& Longnan Region & 6 \\
& Dingxi Region (incl. Baiyin City) & 9 \\
& Lanzhou City & 5 \\
& Linxia Region & 5 \\
& Gannan Region & 7 \\
& Wuwei Region (incl. Jingchang City) & 8 \\
& Zhangye Region & 7 \\
& Jiuquan Region (incl. Jiayuguan City) & 9 \\
Ningxia & Yinchuan City & 2 \\
& Shizuishan City & 2 \\
& Yinnan Region & 4 \\
& Guyuan Region & 6 \\
Qinghai & Haidong Region (incl. Xining City) & 8 \\
& Huangnan Region & 4 \\
\hline
\end{tabular}

underlying factors could be identified. PCA is an iterative method, which means that the first principal component will move towards the greatest covariance. PCA produces as many principal components as variables without any reduction. In order to reduce the variables, their eigenvalue was set to $>1$, which means that the variance of each principal component is at least as great as the variance of a prime variable. In a next step, we used an orthogonal rotation procedure for an even distribution of variance (varimax) and elimination of the iteration effect (Tabachnick \& Fidell 2007). The scores and loadings of the leading rotated principal components were subsequently examined.

\section{RESULTS}

\subsection{General picture of the various types of natural disasters}

On average, the number of natural disasters in the GNQR seems to have increased over time, especially in the case of flooding, hail, frost and dust storms (Fig. 2, Table 2). In terms of the number of disaster years, drought (375 yr), famine (342 yr), flood (310 yr) and hail (285 yr) were shown to be relatively more frequent in affecting the GNQR. Each of them had an 
a

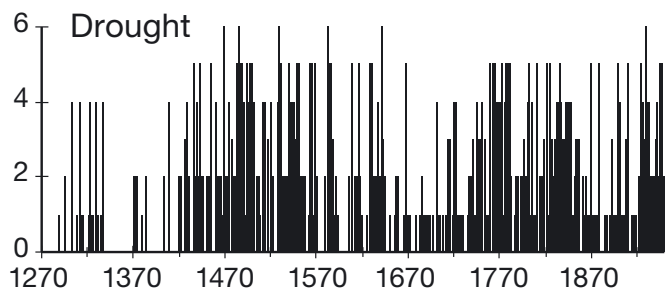

b

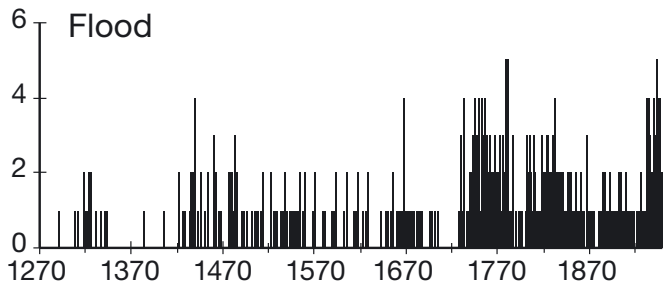

C
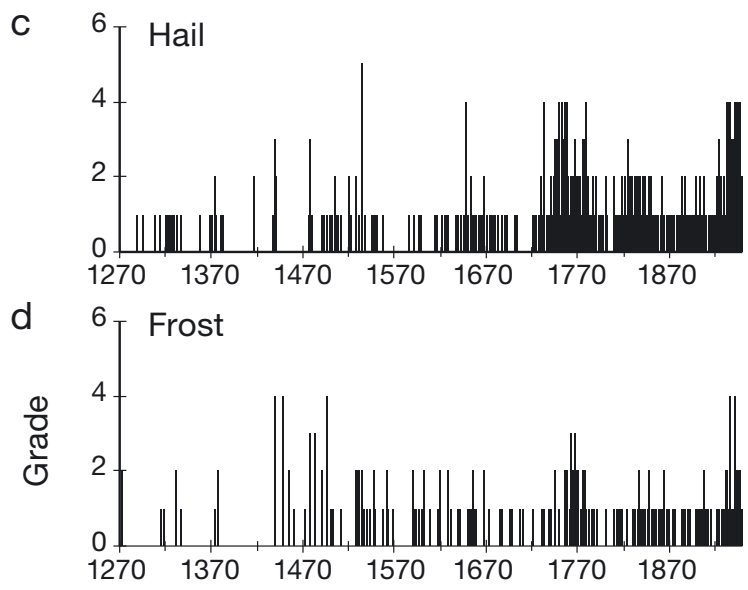

e

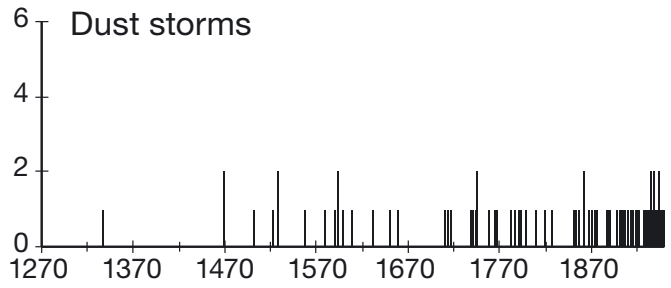

f

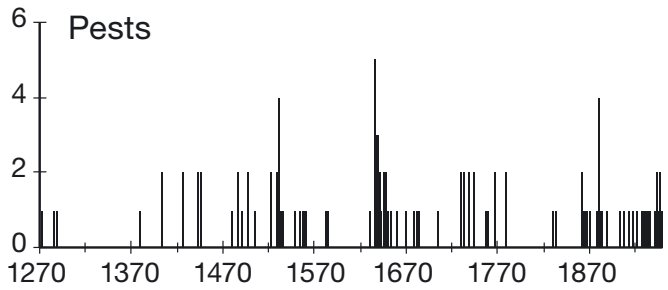

9

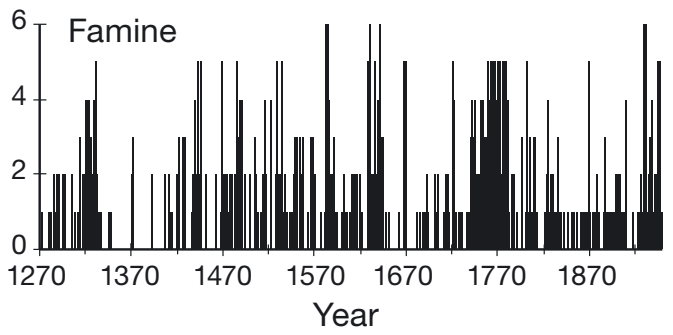

Fig. 2. Time series of 7 types of natural disaster in the GNQR from AD 1270-1949 and their spatial distribution grades (see Section 2 for grade definitions) occurrence over $40 \%$ of the study span. On the other hand, frost and dust storms did not reach Grade 5, revealing their limited areal extent. In contrast, the mean grading showed drought $($ mean $=1.41)$, famine (1.08), flood (0.73) and hail (0.62) to be more rampant in terms of affected areas. The standard deviations of drought $(\mathrm{SD}=1.68)$ and famine $(\mathrm{SD}=1.46)$ were relatively larger, indicating their frequency and magnitude to be more fluctuating in the long run when compared with other disasters. Furthermore, their impacts could be completely devastating in extreme cases.

There were substantial positive linear correlations between the various disasters in the GNQR. Twenty of the 21 cross-correlations were statistically significant (Table 3). In particular, famine correlated with drought, flood and hail. Furthermore, significant intercorrelations were found among frost, flood and hail (Table 3). The overall pattern of cross-correlations suggests the possible presence of common underlying factors among the various types of disasters.

\subsection{Principal components and their interpretation}

The abovementioned inter-connections among the various types of disasters are a prerequisite for applying PCA. Suitability of the data for PCA assessed with the Kaiser-Meyer-Olkin measure of sampling adequacy yielded the value 0.71 , a value that ordinarily would be interpreted as indicating the data were appropriate for PCA (Tabachnick \& Fidell 2007).

PCA of the 7 types of natural disaster in the GNQR extracted 2 leading components (PC1 and PC2) with eigenvalues $>1.0$ that explained $53.55 \%$ of the total variance in natural disaster fluctuation (Table 4). The eigenvalues for the first 2 components suggested that a 2-component solution is the most appropriate for these data (Tabachnick \& Fidell 2007). The 2 principal components were rotated to a varimax criterion. After varimax rotation, PC1 explained $28.58 \%$ of the total variance and PC2 explained $24.97 \%$ (Table 4 ).

Table 5 illustrates the components and their loading patterns for the 7 types of natural disaster examined in the present study. Correlations of the PCA component to the original variables are given by the factor loadings. The factor loadings can be interpreted as the cosine of the angle between the prime variable and the factor. The squares of the loadings correspond to the variances of the factors with respect to the prime variable. To interpret the factors, we set $25 \%$ declared variance as the boundary value (loading $>0.5$ ).

The rotated loading pattern of attribute ratings for PC1 indicates significant contributions of the following disasters: flood, $56 \%$; hail, $64 \%$; frost, $30 \%$; and dust storm, $42 \%$ variance overlap. The rotated loading pat- 
Table 2. Frequency table (percentages in parentheses) of 7 types of natural disaster in the GNQR from AD 1270 to 1949 (See Section 2 for grade definitions)

\begin{tabular}{|lccccccc|}
\hline \multirow{2}{*}{ Grade } & \multicolumn{7}{c}{ Natural disaster } \\
\cline { 2 - 6 } & Drought & Flood & Hail & Frost & Dust storms & Pests & \multirow{2}{*}{ Famine } \\
\hline 0 & 305 & 370 & 395 & 510 & 606 & 590 & 338 \\
& $(44.9)$ & $(54.4)$ & $(58.1)$ & $(75.0)$ & $(89.1)$ & $(86.8)$ & $(49.7)$ \\
1 & 118 & 188 & 197 & 124 & 66 & 63 & 151 \\
& $(17.4)$ & $(27.6)$ & $(29.0)$ & $(18.2)$ & $(9.7)$ & $(9.3)$ & $(22.2)$ \\
2 & 107 & 80 & 56 & 37 & 8 & 22 & 93 \\
& $(15.7)$ & $(11.8)$ & $(8.2)$ & $(5.4)$ & $(1.2)$ & $(3.2)$ & $(13.7)$ \\
3 & 38 & 26 & 16 & 4 & - & 2 & 34 \\
& $(5.6)$ & $(3.8)$ & $(2.4)$ & $(0.6)$ & & $(0.3)$ & $(5.0)$ \\
4 & 56 & 13 & 15 & 5 & - & 2 & 29 \\
& $(8.2)$ & $(1.9)$ & $(2.2)$ & $(0.7)$ & & $(0.3)$ & $(4.3)$ \\
5 & 49 & 3 & 1 & - & - & 1 & 28 \\
& $(7.2)$ & $(0.4)$ & $(0.1)$ & & & $(0.1)$ & $(4.1)$ \\
6 & 7 & - & - & - & - & - & 7 \\
& $(1.0)$ & & & & & & $(1.0)$ \\
Mean & 1.41 & 0.73 & 0.62 & 0.34 & 0.12 & 0.19 & 1.08 \\
SD & 1.68 & 0.99 & 0.91 & 0.68 & 0.36 & 0.55 & 1.46 \\
\hline
\end{tabular}

As we focused on the multi-decadal variability of natural disasters, all of the data were smoothed with a 20 yr moving average which moved to every 10th point (i.e. $10 \mathrm{yr}$, e.g. 1280-1299, 1290-1309, ...) along the temporal data set prior to correlation analysis. Moreover, degrees of freedom of the correlation coefficients were corrected for autocorrelation of the time series by using the Cochrane-Orcutt estimation method. A minimum level of significance of 0.05 was chosen.

\subsubsection{Comparison of PC1 with population pressure}

Natural disasters should not only be regarded as purely physical happenings, but also as the result of human actions. Population growth places increasing numbers of people in hazardous settings. In addition, regional

tern of attribute ratings for PC2 shows significant contributions from: drought, $72 \%$, and famine, $71 \%$ variance overlap.

The above figures reveal that flood, hail, frost and dust storms were triggered simultaneously by PC1, while drought and famine were driven concurrently by PC2. In addition, the PCA demonstrates that pests did not correlate with any of the principal components, thus documenting the independent character of this disaster. The score time series for PC1 and PC2 are shown in Fig. 3.

We interpreted the meaning of PC1 and PC2 by correlating their score time series with various factors which might play a part in causing natural disasters. human activities also trigger disasters (Burton et al. 1993, Wisner et al. 2004). In the historical past, there have been 3 periods of worsening environmental change in northern China, namely the Qin-Han (ca. BC 221-AD 220), Tang-Song (ca. AD 618-1279) and Ming-Qing (ca. AD 1368-1911) dynasties. During the Ming-Qing dynasty, the worst of the 3 periods in terms of environmental change, rapid population expansion and the associated increase of cultivated land and destruction of vegetation resulted in severe environmental degradation and the consequent aggravation of natural disasters (Huang \& Zhang 2004). In recent decades, human actions are also responsible for the frequency, number, extent and impact of natural disas-

Table 3. Correlation matrix (p-values in parentheses) for 7 types of natural disaster in the GNQR from AD 1270-1949, $\mathrm{n}=680$

\begin{tabular}{|c|c|c|c|c|c|c|}
\hline & Flood & Hail & Frost & Dust storms & Pests & Famine \\
\hline Drought & $\begin{array}{c}0.25 \\
(0.000)\end{array}$ & $\begin{array}{c}0.24 \\
(0.000)\end{array}$ & $\begin{array}{c}0.27 \\
(0.000)\end{array}$ & $\begin{array}{c}0.06 \\
(0.104)\end{array}$ & $\begin{array}{c}0.12 \\
(0.001)\end{array}$ & $\begin{array}{c}0.53 \\
(0.000)\end{array}$ \\
\hline Flood & & $\begin{array}{c}0.67 \\
(0.000)\end{array}$ & $\begin{array}{c}0.33 \\
(0.000)\end{array}$ & $\begin{array}{c}0.22 \\
(0.000)\end{array}$ & $\begin{array}{c}0.14 \\
(0.000)\end{array}$ & $\begin{array}{c}0.33 \\
(0.000)\end{array}$ \\
\hline Hail & & & $\begin{array}{c}0.37 \\
(0.000)\end{array}$ & $\begin{array}{c}0.29 \\
(0.000)\end{array}$ & $\begin{array}{c}0.20 \\
(0.000)\end{array}$ & $\begin{array}{c}0.32 \\
(0.000)\end{array}$ \\
\hline Frost & & & & $\begin{array}{c}0.18 \\
(0.000)\end{array}$ & $\begin{array}{c}0.10 \\
(0.011)\end{array}$ & $\begin{array}{c}0.19 \\
(0.000)\end{array}$ \\
\hline Dust storms & & & & & $\begin{array}{c}0.15 \\
(0.000)\end{array}$ & $\begin{array}{c}0.10 \\
(0.010)\end{array}$ \\
\hline Pests & & & & & & $\begin{array}{c}0.23 \\
(0.000)\end{array}$ \\
\hline
\end{tabular}


Table 4. Eigenvalues and variances of factor extraction by principal component analysis. Var. $=\%$ variance, $\mathrm{Cum}=$ cumulative $\%$

\begin{tabular}{|ccccccccc|}
\hline \multirow{2}{*}{ PC } & \multicolumn{3}{c}{ Prime eigenvalues } & & \multicolumn{3}{c|}{ Rotated sum of squared loadings } \\
& Total & Var. & Cum. & & Total & Var. & Cum. \\
\hline & & & & & & & \\
1 & 2.611 & 37.297 & 37.297 & & 2.001 & 28.579 & 28.579 \\
2 & 1.137 & 16.250 & 53.547 & & 1.748 & 24.967 & 53.547 \\
\hline
\end{tabular}

Table 5. Rotated principal component matrix and loading values for 7 types of natural disaster in the GNQR. The corresponding factors of each component (with declared variance in excess of $25 \%$ ) are highlighted in bold

\begin{tabular}{|lcr|}
\hline Natural disaster & PC1 & PC2 \\
\hline Drought & 0.06 & $\mathbf{0 . 8 5}$ \\
Flood & $\mathbf{0 . 7 5}$ & 0.30 \\
Hail & $\mathbf{0 . 8 0}$ & 0.26 \\
Frost & $\mathbf{0 . 5 5}$ & 0.26 \\
Dust storms & $\mathbf{0 . 6 5}$ & -0.14 \\
Pests & 0.23 & 0.30 \\
Famine & 0.15 & $\mathbf{0 . 8 4}$ \\
\hline
\end{tabular}
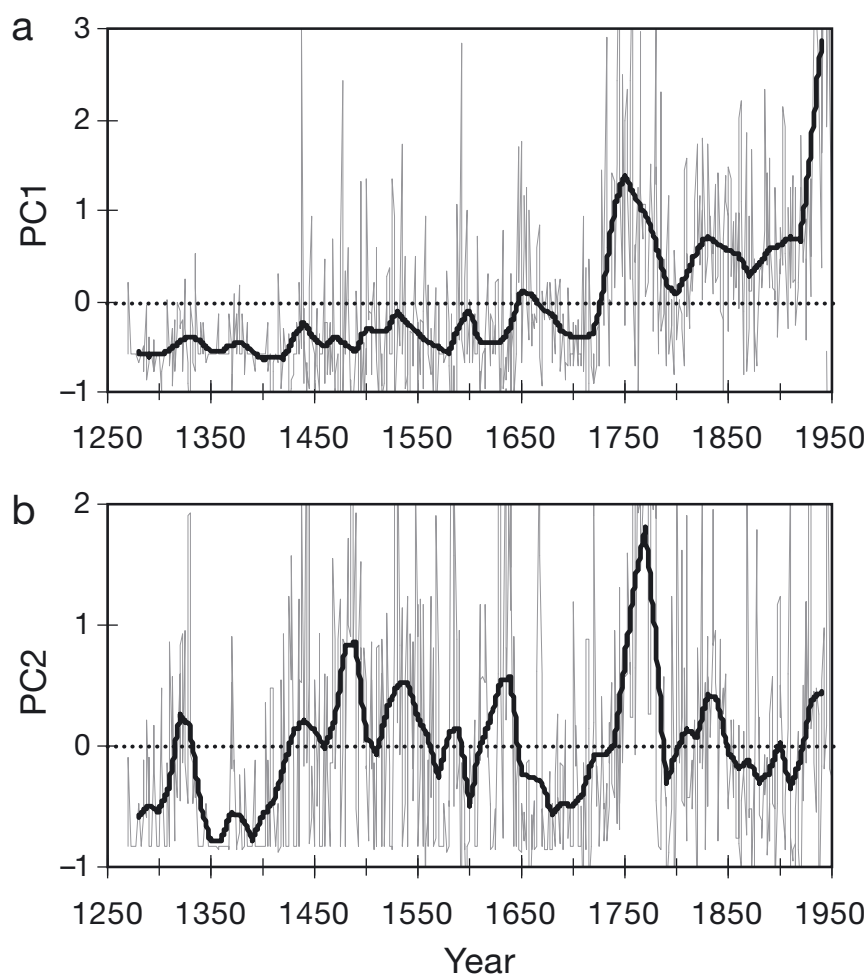

Fig. 3. Scores from the first 2 rotated principal components of 7 types of natural disaster in the GNQR. (a) PC1; (b) PC2. Bold black line represents the $20 \mathrm{yr}$ moving average which moved to every 10 th point along the score time series (see Section 3.2). The corresponding values are plotted at the centers of each $20 \mathrm{yr}$ window period ters in China (Liu \& Diamond 2005). Therefore, we hypothesized PC1 to be related to population pressure, and we compared it with the historical population parameters of the GNQR, namely population size and population growth rate, for verification.

Population size: Based on Chinese historical materials, several scholars have endeavored to get the best possible historical estimates of Chinese population size within the current political boundary of China. Given that Zhao \& Xie's (1988) population estimate (spanning $\mathrm{BC} 684-\mathrm{AD}$ 1984) is believed to be the most detailed and has been repeatedly used by other scholars (Chu \& Lee 1994, Turchin 2005), it has been employed in the present study. Zhao \& Xie (1988) also give historical population estimates at the provincial level based on the current provincial political boundaries of China. As Zhao \& Xie (1988) give estimates of Chinese population size at irregular time intervals, the common logarithm of the data points was taken, linearly interpolated and then anti-logged back, to create an annual time series for each province or autonomous region. This method avoids any distortions of population growth rate in data interpolation. We then added the population series of Gansu, Ningxia and Qing to give the population size of the GNQR.

Population growth rate: Based upon Zhao \& Xie's (1988) population size data, population growth rate was calculated by:

$$
\frac{P_{t}-P_{t-1}}{P_{t-1}} \times 100
$$

where $P$ is the population size and $t$ represents time step (1 yr).

The multi-decadal variability of the scores for PC1 was negative (i.e. below average) from AD 1270 to the 1730 s and positive (i.e. above average) from that point forward, which is similar to the variability in population size (Fig. 4a). The correlation between PC1 and population size was strong. Although correlation between PC1 and population growth rate was not as strong as that between PC1 and population size, their peaks and troughs were basically coincident, particularly with regard to the later period (Fig. 4b). It may be argued that the upward trend in flood, hail, frost and dust storms is attributable to the production of an increasing number of historical records over time. However, the good match of peaks and troughs between PC1 and the 2 population parameters indicates that population pressure (the combination of population size and population growth) better explains the frequency and areal extent of flood, hail, frost and dust storms. 

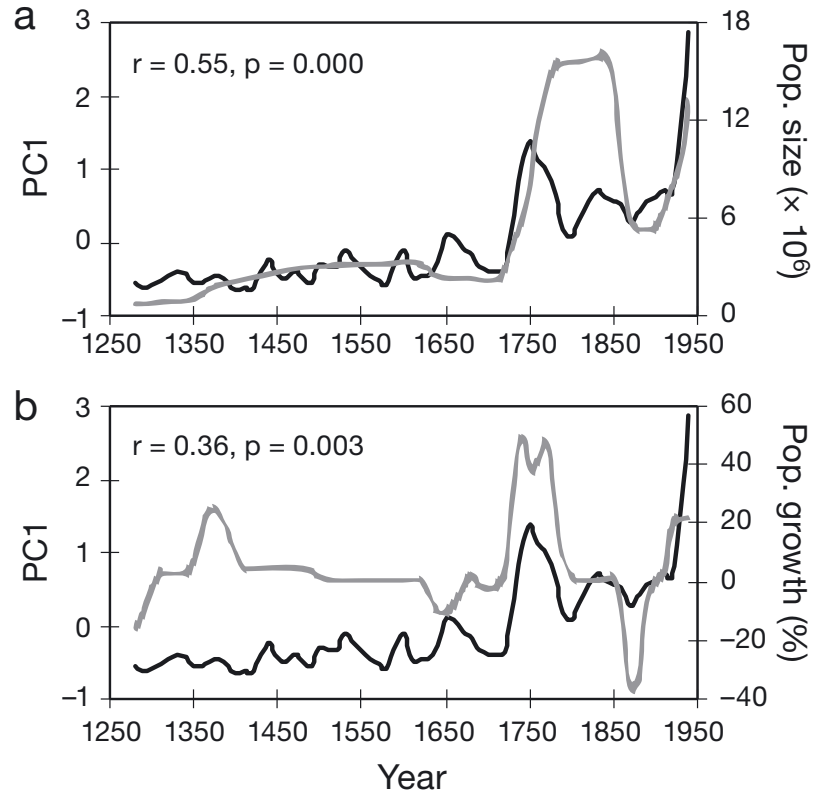

Fig. 4. Comparisons between PC1 (black lines, left axes) and (a) population size and (b) population growth rate (grey lines, right axes) of the GNQR (Zhao \& Xie 1988). All data were smoothed with a $20 \mathrm{yr}$ moving average which moves to every 10th point along the time series (see Section 3.2). The corresponding values are plotted at the centers of the $20 \mathrm{yr}$ window periods. Sample size for the correlation coefficients is $n=67$. Degrees of freedom of the correlation coefficients were corrected for autocorrelation of the time series by using the Cochrane-Orcutt estimation method

\subsubsection{Comparison of PC2 with atmospheric circulation}

Drought and famine are different from other disasters in that they develop slowly, sometimes over years, and their onset can be masked by a number of factors. We found that famine was more correlated with drought in comparison with other disasters (Table 3), which suggests that drought might be the most common cause of famine. Throughout history, the food supply of humankind has been, at best, highly precarious. Frequent drought reduces grain yields and, in some years, results in no harvest at all. It tends to have its worst impact on land that is already arid, resulting in enormous economic losses and food deprivation for peasants (Davis 2002). In addition, famines caused by drought are often larger in extent, more severe in magnitude and longer in duration (Xie \& Fu 2004).

Atmospheric circulation plays an important role in the global climate system. Because previous research showed a significant relationship between atmospheric circulation and the precipitation anomalies over China (Xin et al. 2006, Su \& Wang 2007, Chu et al. 2008, Wei et al. 2008), we hypothesized PC2 to be related to atmospheric circulation, and we compared it with some gen- eral atmospheric circulation parameters in the Northern Hemisphere for verification. Three atmospheric circulation parameters were selected to investigate their possible influence on PC2 in the GNQR. They are as follows:

(1) El Niño-Southern Oscillation (ENSO): a global, coupled ocean-atmosphere phenomenon. ENSO events cause a warming in tropical Pacific and Indian Oceans. Our ENSO index is derived from the quality adjusted magnitude score of ENSO events back to AD 1525 (Gergis \& Fowler 2009). The score was derived from tree-ring chronologies, coral sequences, documentary records of drought and flood and ice-core data from core ENSO or key teleconnection areas previously identified as containing an ENSO signal from both eastern and western Pacific locations.

(2) Pacific Decadal Oscillation (PDO): the index of PDO is defined as the time coefficient of the first empirical orthogonal function component of multidecadal variability in sea surface temperature anomalies in the extra-tropical North Pacific. Positive phases of the PDO are typified by warm sea surface temperatures in the northeastern Pacific. Our PDO index was developed from living and dead Pinus flexilis trees occurring in open groves on rocky substrates in California and Alberta (MacDonald \& Case 2005). Those 2 sites lie at opposite ends of the PDO precipitation dipole.

(3) North Atlantic Oscillation (NAO): a climatic phenomenon in the North Atlantic Ocean of fluctuations in the difference of atmospheric pressure at sea level between the Icelandic Low and Azores High. The increased pressure difference between the Azores High and Icelandic Low during positive NAO phase results in enhanced zonal flow. Our NAO index is defined as the difference of the aridity threshold proxies between Scotland and Morocco (Trouet et al. 2009). These proxy records are located centrally in the opposing poles of NAO.

The 3 indices above were downloaded from the World Data Center for Paleoclimatology (www.ncdc. noaa.gov/paleo/recons.html). Since the ENSO reconstruction only extends back to AD 1525, for comparison purposes we considered only the data points since AD 1525 for the other indices.

Correlation results showed that the correlation coefficient between PC2 and ENSO was negatively significant, while the negative correlation between PC2 and NAO was not quite significant. However, the correlation between PC2 and PDO was not significant (Fig. 5). We also correlated PC2 with other regional climatic parameters such as the temperature of the mideastern Tibetan plateau (Liu et al. 2009), the level of precipitation of northeastern Qinghai (Sheppard et al. 2004) and Asian monsoon records derived from the Wanxiang Cave in Gansu (Zhang et al. 2008b). However, none of these correlations were statistically signif- 
icant (data not shown). This indicates atmospheric circulation to be more pertinent than regional climate in causing drought and famine at the multi-decadal scale.

Even though PC2 negatively correlated with ENSO and NAO, we spotted a sharp difference in the correlations before and after AD 1700. To further verify this, sequence splitting was done (AD 1530s-1740s, 1630s1840s and 1730s-1940s), and the correlation analysis between PC2 and the various atmospheric circulation parameters was repeated (Table 6). Although the correlation between PC2 and ENSO was no longer statistically significant after sequence splitting, we found that the negative association between PC2 and ENSO became stronger over the 3 periods (Table 6). On the other hand, the contrasting correlation between $\mathrm{PC} 2$ and NAO before and after AD 1700 is worth mentioning. The correlation from the AD 1530s-1740s was positive, while those from the AD 1630s-1840s and 1730s-1940s were strongly negative (Table 6). The correlation between PC2 and PDO was not statistically significant across these 3 periods.

\section{DISCUSSION}

\subsection{Population pressure and natural disasters}

In the agrarian society of historical China, farming was the most important means of sustaining life. With the arrival of new migrations, forest and other natural vegetation was cleared to create farmland. Historically, the GNQR was sparsely populated. The region's population increased very slowly from 1.1 million to 3.3 million from $\mathrm{AD} 1270$ to 1626 . At that time, the population size was reduced to 2.2 million (as recorded in

Table 6. Correlation coefficients (p-values in parentheses) between PC2 with various atmospheric circulation parameters in different periods. All data were smoothed with a $20 \mathrm{yr}$ moving average which moves to every 10th point along the time series prior to statistical analysis (see Section 3.2). $\mathrm{n}=22$ data points. Degrees of freedom of the correlation coefficients were corrected for autocorrelation of the time series by using the Cochrane-Orcutt estimation method. ENSO: El Niño Southern Oscillation; PDO: Pacific Decadal Oscillation; NAO: North Atlantic Oscillation

\begin{tabular}{|lccc|}
\hline \multirow{2}{*}{$\begin{array}{c}\text { Atmospheric } \\
\text { circulation }\end{array}$} & \multicolumn{3}{c|}{ Time period } \\
\cline { 2 - 4 } parameter & $1530 \mathrm{~s}-1740 \mathrm{~s}$ & $1630 \mathrm{~s}-1840 \mathrm{~s}$ & $1730 \mathrm{~s}-1940 \mathrm{~s}$ \\
\hline ENSO & & & \\
& -0.35 & -0.37 & -0.41 \\
PDO & $(0.125)$ & $(0.105)$ & $(0.075)$ \\
& -0.01 & 0.16 & -0.03 \\
NAO & $(0.957)$ & $(0.499)$ & $(0.918)$ \\
& 0.34 & -0.49 & -0.73 \\
& $(0.143)$ & $(0.027)$ & $(0.000)$ \\
\hline
\end{tabular}
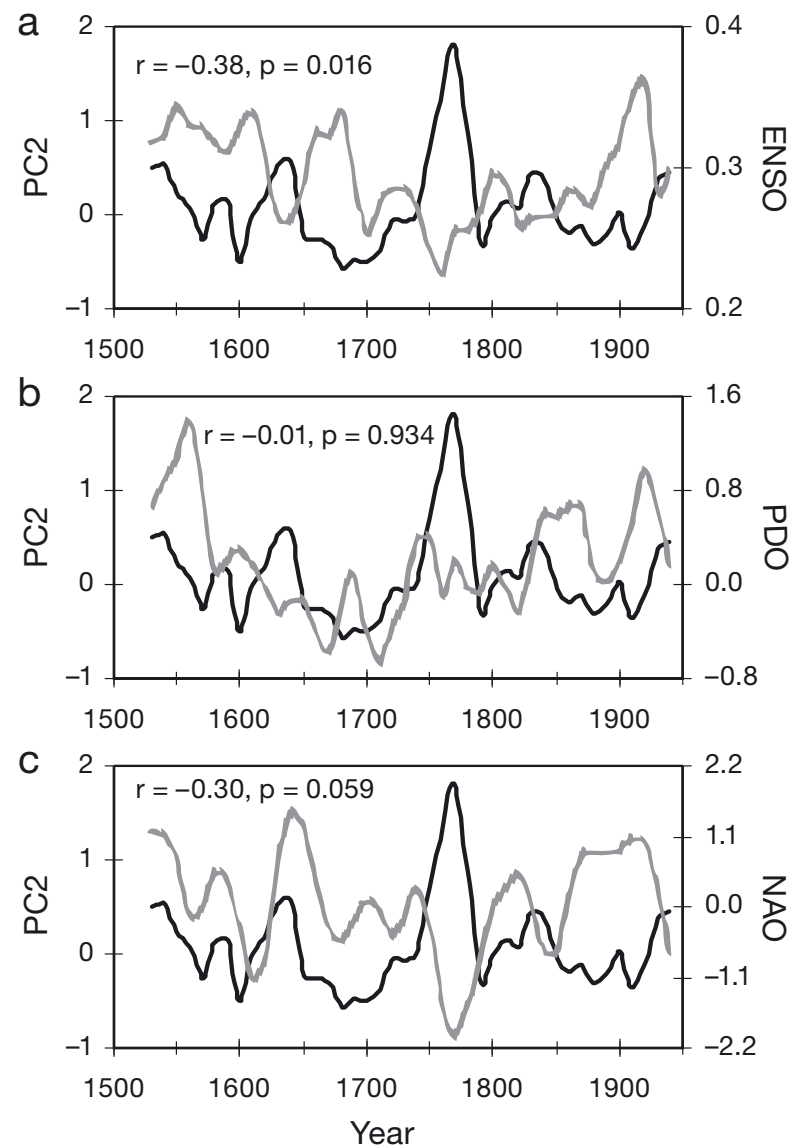

Fig. 5. Comparisons between PC2 (black, left axes) and the (a) El Niño Southern Oscillation (ENSO; grey, right axis) (Gergis \& Fowler 2009), (b) Pacific Decadal Oscillation (PDO; grey, right axis) (MacDonald \& Case 2005), and (c) North Atlantic Oscillation (NAO; grey, right axis) (Trouet et al. 2009) indexes. All data were smoothed with a $20 \mathrm{yr}$ moving average which moves to every 10th point along the time series (see Section 3.2). The corresponding values are plotted at the centers of the $20 \mathrm{yr}$ window periods. Sample size for the correlation coefficients is $n=42$. Degrees of freedom of the correlation coefficients were corrected for autocorrelation of the time series by using the Cochrane-Orcutt estimation method

AD 1661) by late-Ming peasant rebellions and the Manchu conquest (Zhao \& Xie 1988). The situation has changed markedly since the early Qing dynasty. The tremendous population expansion ${ }^{1}$ spurred by a prolonged period of peace led to a severe shortage of arable land in central and southern China, which forced the landless and land-poor households to migrate to northeastern and northwestern China for a living. Migration of the poor and landless was further facilitated by the merging of 'ting quota' and 'land tax'

1Population size in China increased from 88 million to 400 million from 1661 to 1830 (Zhao \& Xie 1988).

${ }^{2}$ By paying more land tax, people did not have to perform compulsory labor and military services 
during the reign of the Yongzheng Emperor (ca. AD 1723-1735) (Bin 2007). GNQR has served as a major region for pioneering settlement since the early 18th century and was characterized by a high population growth rate (Ho 1959, Jiang 1993). In addition, the benign climate throughout the 18th century (Liu et al. 2009) augmented the land carrying capacity in the GNQR, which made population expansion possible. In $\mathrm{AD} 1786$, the population size in the GNQR reached 15.4 million (Zhao \& Xie 1988).

During the period of population expansion, people reclaimed lands previously deemed unsuitable for agricultural use (hilly, sandy, marshy and other lowlying lands) to feed the growing population. Furthermore, the reclamation of marginal lands was encouraged by the Qing government out of military and economic concern (Zhao 2006). This led to severe environmental problems and resulted in various natural disasters. For instance, when people converted mountainous areas into terraced fields, the direct effect was soil erosion with increased sediments in lower reaches. Land reclamation activities surrounding large lakes reduced lake sizes and flood storage capacity. The construction of levees caused flood levels to rise due to restricted flood discharge capacity. This increased the incidence of flood in the long run (Ho 1959, Jiang 1993). In parallel, when people reclaimed desert land for agricultural uses, those agriculturally marginal lands were abandoned quickly owing to the consequent soil problems such as erosion, salinization and soil fertility losses. Afterwards, other pieces of wasteland were reclaimed for replacement. Such unsustainable practices upset the already fragile ecology in northwestern China and became harmful to long-term agricultural production. Indeed, most of the farming areas in northwestern China underwent severe soil erosion and desertification (Chao 1986, Zhao 2006). Further, overgrazing, erosion, grassland degradation and desertification have led to more frequent and severe dust storms (Liu \& Diamond 2005).

The local land carrying capacity of arid northwestern China was exceeded around AD 1800 (Wang et al. 2002). Although the population in the GNQR was still growing, it grew at a very slow rate. By AD 1860, the population in the GNQR reached 15.9 million. Shortly thereafter, the population dropped as a result of wars and natural calamities. The Muslim Rebellion in AD 1862-1873 depopulated Gansu considerably, as nearly 50 of the province's 70 counties suffered heavy population losses during the turmoil (Ho 1959). Severe drought in AD 1866 and 1877-1878 and the associated population checks (famine, epidemics and out-migration) also depopulated northwestern China (Yang 2008). Consequently, the population in the GNQR dropped from 15.9 million to 5.2 million during the period (Zhao \& Xie 1988). Yet the population expanded again in the years after the Qing dynasty, and population pressure returned to the region. This population oscillation pattern basically captures the long-term trend of flood, hail, frost and dust storms in the GNQR.

It should be noted that hail and frost are basically meteorological phenomena, which are largely independent of population-induced environmental degradation. How can we explain, then, the positive correlation between the 2 meteorological disasters and our population parameters? Recall that the potential for natural disasters is contingent upon the characteristics of hazardous events (their magnitude, frequency, duration, areal extent, speed of onset, spatial dispersion and temporal spacing) and whether the affected areas are used by people (Burton et al. 1993). Even though man does not directly cause hail and frost, the reported occurrence of the 2 disasters will be positively correlated with population pressure (i.e. there will be more reported occurrences when more people live in the affected areas). This phenomenon may be somehow relevant to every type of natural disaster. However, it is predominantly significant for those disasters which are characterized by short duration and limited areal extent, like hail and frost (Burton et al. 1993).

\subsection{Atmospheric circulation and natural disasters}

The key system that bridges the warm events in the Eastern Pacific (ENSO) and the winter monsoon is a lower-tropospheric anticyclone located in the western North Pacific. The western North Pacific wind anomalies develop rapidly in late fall of the year when ENSO matures. The anomalies persist until the following spring or early summer, causing anomalous wet conditions along the East Asian polar front stretching from southern China northeastward to the east of Japan (Wang et al. 2000). Thereby, northwestern China is wetter than average during the positive ENSO phase (Su \& Wang 2007). In parallel, a positive mode of the NAO causes northward-displaced, stronger-thanaverage mid-latitude westerlies with an enhanced latitudinal water vapor gradient into the central Asian drylands. Northwestern China therefore experiences ameliorated environmental conditions with enhanced moisture availability and reduced drought length and frequency ( $\mathrm{Yu}$ et al. 2006). Given that both positive modes of ENSO and NAO bring about increased moisture, resulting in reduced drought frequency and intensity, the negative correlations between PC2 and ENSO and between PC2 and NAO in the later periods (i.e. AD 1630s-1840s and 1730s-1940s) were justified.

But what about the out-of-phase association between PC2 and ENSO and between PC2 and NAO in the 
earlier period (i.e. AD 1530s-1740s)? Given that solar activity controls the motion of the north edge of the Asian summer monsoon by affecting the intensity of the Asia summer monsoon and winter monsoon and the locations of westerlies, further dominating precipitation variations of northwestern China (Tan et al. 2008), we proposed that the out-of-phase association in the earlier period may be related to the centennial temperature change in high latitudes of the Northern Hemisphere.

From the 15th to 17th centuries, Little Ice Age cooling occurred in arid central Asia (Yang et al. 2009). The cooling event was also synchronous in the mid-eastern Tibetan Plateau (Liu et al. 2009), the whole of China (Yang et al. 2002) and the Northern Hemisphere (Moberg et al. 2005) (Fig. 6), and was accompanied by a southerly shift in the Intertropical Convergence Zone and weakening Asian monsoon intensity in northwestern China (Zhang et al. 2008a). Since oceanic and terrestrial heat capacity are different, when solar activity decreases, the temperature of land decreases quickly. The Tibetan Plateau is a heat sink which further magnifies such differences between the Asian continent and its surrounding ocean. The Asian summer monsoon is weakened and the winter monsoon is strengthened, which leads the north edge of the Asian summer monsoon to move south. At the same time, the decrease of solar activity forces the westerlies to migrate southward (Tan et al. 2008). Equatorward displacement of the East Asian Jet Stream also follows.

The East Asian Jet Stream stretches from north China to the central North Pacific. During June, the jet core is located around Japan, and China and Korea are located to the west of the jet core, in the upstream region. Crossjet circulation affects rainfall location relative to the jet, and the direct meridional circulation is dominant at the upstream region. After a positive winter NAO, the jet flow pattern around Korea in June shifts southward, which accelerates subsidence over the northern area of the jet stream and suppresses convective precipitation in the following summer (Sung et al. 2006).

The southward shifting of monsoons, westerlies and the East Asian Jet Stream during the Little Ice Age has the following implications. As the East Asian polar front moved equatorward away from the GNQR during the Little Ice Age, the influence of ENSO upon the region became weak. This explains the weak negative correlation between PC2 and ENSO in the period $\mathrm{AD}$ $1530 \mathrm{~s}-1740 \mathrm{~s}$. At the same time, the influence of westerlies upon the region also became weak. The southward shift of the East Asian Jet Stream means that the GNQR might have positioned within the area north of the jet stream, and summer precipitation over the GNQR might be suppressed after positive NAO events. This leads to the positive correlation between PC2 and NAO.
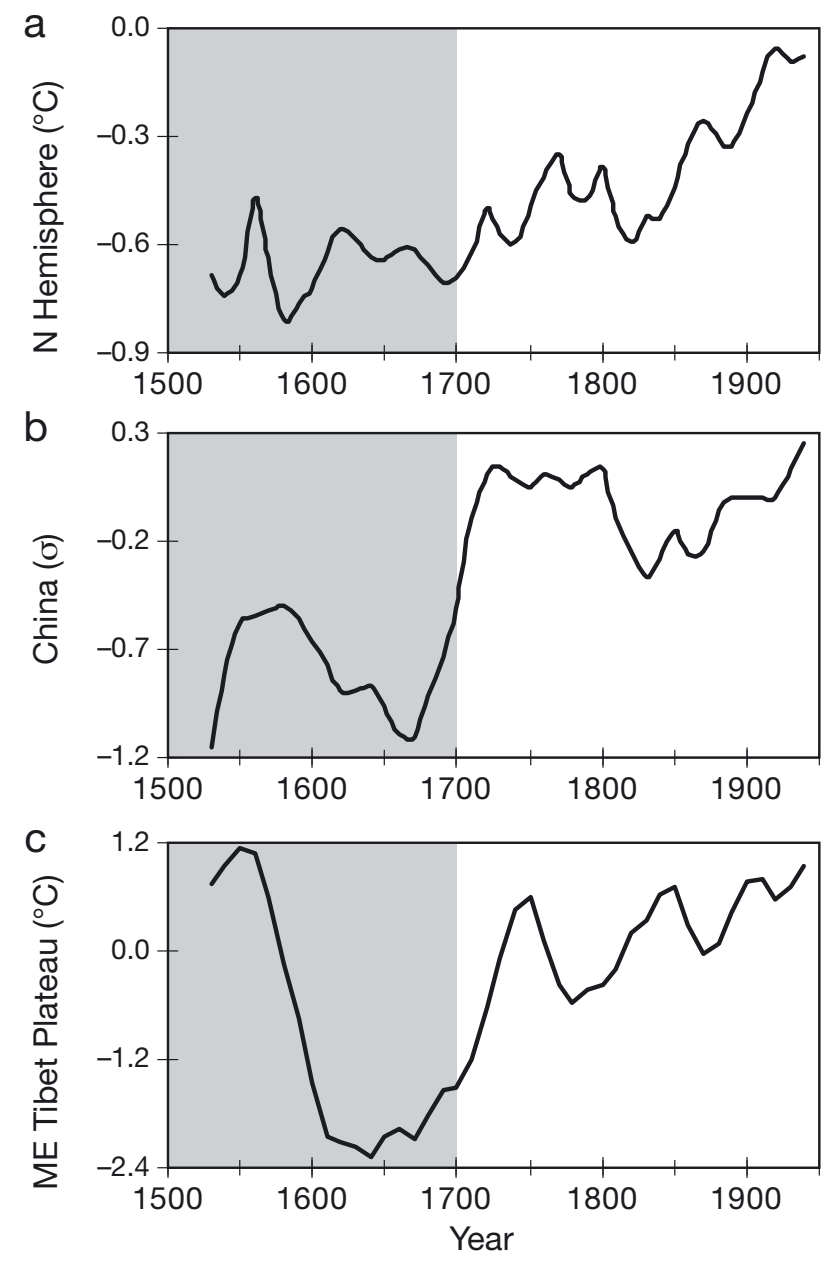

Fig. 6. Paleo-temperature reconstructions $\left({ }^{\circ} \mathrm{C}\right.$ or sigma units) for (a) the Northern Hemisphere (Moberg et al. 2005), (b) China (Yang et al. 2002), and (c) the mid-eastern (ME) Tibetan Plateau (Liu et al. 2009). Grey shaded area represents the Little Ice Age cooling in arid Central Asia (Yang et al. 2009). All data have been smoothed with a $20 \mathrm{yr}$ moving average which moves to every 10th point along the time series (see Section 3.2). The corresponding values are plotted at the centers of the $20 \mathrm{yr}$ window periods

In contrast, when temperature increased quickly after the 17 th century, the Tibetan Plateau became a heat source and the intense heating of the plateau surface caused a strong uplift motion of air mass. The resultant low pressure in the low troposphere near the land surface led to a large-scale convergence and enhancement of the Asian summer monsoon. The winter monsoon was weakened. The north edge of the Asian summer monsoon, westerlies and East Asian Jet Stream moved northward synchronously (Tan et al. 2008). GNQR was then exempted from the precipitation suppression effect after positive NAO events. Further, the region became dominated by the enhanced moisture effect after positive NAO events via the westerlies. The positive as- 
sociation between El Niño and moisture supply also became more apparent in the GNQR.

Some scholars (Böhner 2006, Sato 2009) suggest that the precipitation in arid Central Asia (including Northwestern China) in recent decades is not maintained by moisture evapotranspired in tropical regions (e.g. Asian summer monsoon) or adjacent areas. Precipitation in arid Central Asia depends mainly on the amount of water vapor transported by the mid-latitude westerlies from the North Atlantic Ocean and from inland seas and lakes along the westerly cyclonic storm paths. This explains why the correlation between PC2 and NAO in the AD 1730s-1940s was stronger than that between PC2 and ENSO (Table 6).

The reasons for drought and famine are likewise more complex than those for all other natural disasters. Along with nature and the changing state of the earth, there are distinctly human, economic, cultural and political causes for both drought and famine (Davis 2002). But the good coherences among PC2, ENSO and NAO show that physical factors may be more important in driving drought and famine in the GNQR.

\subsection{Pests}

In the GNQR, over $90 \%$ of the pest disasters were related to locust plagues (Yuan 1994). Locusts are potentially the most destructive insect pests in the world. When weather and ecological conditions favor breeding, locusts are forced into a small area. They stop acting as individuals and start acting as a group. Within a few months, huge swarms form and fly downwind in search of food (Zhu 1999).

Northwestern China is mainly affected by 2 subspecies of locusts: Locusta migratoria manilensis (Meyen) and L. m. migratoria (Linnaeus). Over $90 \%$ of the locust calamities in Chinese history have been caused by the former (Zhu 1999). The main source of locust plagues in China has historically been the marshland associated with overflow channels and flood lakes connecting the lower reaches of the river systems. It has been shown that locust outbreaks in history typically occurred in drought years or years after floods. In drought years, suitable habitat for the locusts to lay eggs exists along riverbanks and lakesides as the water level recedes. Similarly, in years after floods, suitable habitat is provided in formerly flooded areas. Briefly, the mechanisms behind the locust plagues are direct and delayed effects of drought and flood on the breeding habitat of the locusts (Zhang \& Li 1999). The above flood/droughtlocust link is mediated by decadal and centennial temperature forcing of floods and droughts, as high flood and drought frequencies tended to occur during cold periods in history (Stige et al. 2007, Zhang et al. 2009).

\section{CONCLUSIONS}

By using historical data, the present study gives a brief overview of the natural disasters in the GNQR in northwestern China. Their underlying causes have also been retrieved by PCA. Two rotated principal components explained $53.55 \%$ of the temporal variance of the various natural disasters. PC1 had flood, hail, frost and dust storms loading on it, which positively correlated with population pressure. PC2 had drought and famine loading on it, which were significantly linked to atmospheric circulation. These 2 components explain nearly equal proportions of variance in the entire data set. However, the remaining variance $(46.45 \%)$ is substantial, and is, in part, attributable to the independent character of pest disasters. On the other hand, it may be related to the social, political and economic factors that underline the impact of natural disasters (Wisner et al. 2004). Nonetheless, we found that the frequencies and areal extents of drought, famine and pest disasters were somehow mediated by low-frequency temperature forcing. This indicates temperature change may be responsible for the remaining variance, a possibility which should be further examined.

The present study covered the period from AD 1270 to 1949 . Since the 1950 s, average global temperature has continued to rise (Jansen et al. 2007). The warmth is forced by both anthropogenic factors and natural climatic cycles, which may have advanced the deterioration of the fragile ecosystems in northwestern China. Atmospheric circulation has also become more anomalous during the recent warming. Hence the relationship between atmospheric circulation and natural disasters may have changed over time. What is known for certain is that, owing to the interplay of the East Asian summer monsoon with the westerlies at the boundary of the Asian summer monsoon limit, variations in the aridity threshold regime triggered by atmospheric circulation changes will be more pronounced in northwestern China than in other monsoon regions. The effects of an expanding population and the associated environmental degradation in northwestern China should also not be overlooked.

In northwestern China, discharge of the majority of rivers has been drastically reduced (even dried up), river courses have been shortened and terminal lakes have contracted or dried up. Land desertification and soil salinization have developed rapidly. Vegetation is degrading and biodiversity is decreasing, as compared with the early $1950 \mathrm{~s}$; the natural grassland area has decreased by 16 to $75.4 \%$ (Wang \& Cheng 2000). At the same time, agriculture is still only partially mechanized. Irrigation is limited by the increasing competition for water resources between various economic sectors and by more restrictive regulations from the 
government (Deng et al. 2005). In terms of physical productivity and socioeconomic capability to adapt, northwestern China is the region in China with the highest agricultural vulnerability (Lin 1996). The combination of the above factors increases northwestern China's societal vulnerability to natural disasters, especially drought. Our results relating to the longterm variability of natural disasters in the GNQR should be treated as an impetus for further empirical work. Data of longer time span and higher spatial resolution are needed to further investigate how lowfrequency solar forcing affects the variability of natural disasters.

Acknowledgements. We gratefully acknowledge the research grant generously provided by the HKU Small Project Funding for completion of the project entitled 'The Spatio-temporal Dynamics of Natural Disasters in Historical China' (200807176038); HKU Seed Funding for Basic Research for the project entitled 'Long-term Climate Change and the Seventeenth-Century General Crisis in Europe' (10400340); and Research Grants Council of The Government of the Hong Kong Special Administrative Region of the People's Republic of China for the project entitled 'Climate Change and War-Peace Cycles in Eurasia in Recent Human History' (HKU7055/08H). We also thank P. Taravov (Institut für Geologische Wissenschaften, Freie Universität Berlin, Germany) for providing precipitation reconstruction of northeastern Qinghai.

\section{LITERATURE CITED}

Barlow M, Cullen H, Lyon B (2002) Drought in Central and Southwest Asia: La Niña, the warm pool, and Indian Ocean precipitation. J Clim 15:697-700

Bin J (2007) Population migration in the middle of the Qing dynasty. Northwest Popul 28:93-96

Böhner J (2006) General climatic controls and topoclimatic variations in Central and High Asia. Boreas 35:279-295

Burton I, Kates RW, White GF (1993) The environment as hazard. Guilford Press, New York

Chao K (1986) Man and land in Chinese history: an economic analysis. Stanford University Press, Stanford, CA

> Chu CYC, Lee RD (1994) Famine, revolt, and the dynastic cycle: population dynamics in historical China. J Popul Econ 7:351-378

Chu G, Sun Q, Wang X, Sun J (2008) Snow anomaly events from historical documents in eastern China during the past two millennia and implication for low-frequency variability of AO/NAO and PDO. Geophys Res Lett 35:L14806 doi:10.1029/2008GL034475

Davis L (2002) Natural disasters. Facts on File, New York

> Deng X, Luo Y, Dong S, Yang X (2005) Impact of resources and technology on farm production in northwestern China. Agric Syst 84:155-169

Easterling DR, Meehl GA, Parmesan C, Changnon SA, Karl TR, Mearns LO (2000) Climate extremes: observations, modeling, and impacts. Science 289:2068-2074

Gergis JL, Fowler AM (2009) A history of ENSO events since AD 1525: implications for future climate change. Clim Change 92:343-387

Glaser R, Stangl H (2003) Historical floods in the Dutch Rhine delta. Nat Hazards Earth Syst Sci 3:605-613
Helmer M (2006) Natural disasters and climate change. Disasters 30:1-4

Ho PT (1959) Studies on the population of China, 1368-1953. Harvard University Press, Cambridge

Huang Z, Zhang W (2004) Climate fluctuation and natural disasters during historical periods in tropics of China. J Nat Disasters 13:58-63

Jansen E, Overpeck J, Briffa KR, Duplessy JC and others (2007) Palaeoclimate. In: Solomon S, Qin D, Manning M, Chen Z and others (eds) Climate change 2007: the physical science basis. Contribution of Working Group I to the Fourth Assessment Report of the Intergovernmental Panel on Climate Change. Cambridge University Press, Cambridge, p 433-498

Jiang T (1993) Zhongguo jindai renkou shi. Hangzhou University Press, Hangzhou

Jiang T, Zhang Q, Blender R, Fraedrich K (2005) Yangtze Delta floods and droughts of the last millennium: abrupt changes and long term memory. Theor Appl Climatol 82:131-141

Jiang T, Zhang Q, Zhu D, Wu Y (2006) Yangtze floods and droughts (China) and teleconnections with ENSO activities (1470-2003). Quaternary Int 144:29-37

Lin E (1996) Agricultural vulnerability and adaptation to global warming in china. Water Air Soil Pollut 92:63-73

> Liu J, Diamond J (2005) China's environment in a globalizing world. Nature 435:1179-1186

> Liu K, Shen C, Louie K (2001) A 1,000-year history of typhoon landfalls in Guangdong, southern China, reconstructed from Chinese historical documentary records. Ann Assoc Am Geogr 91:453-464

> Liu Y, An Z, Linderholm HW, Chen D and others (2009) Annual temperatures during the last 2485 years in the mid-eastern Tibetan Plateau inferred from tree rings. Sci China D Earth Sci 52:348-359

MacDonald GM, Case RA (2005) Variations in the Pacific Decadal Oscillation over the past millennium. Geophys Res Lett 32:L08703 doi:10.1029/2005GL022478

McCabe GJ, Palecki MA, Betancourt JL (2004) Pacific and Atlantic Ocean influences on multidecadal drought frequency in the United States. Proc Natl Acad Sci USA 101: 4136-4141

Moberg A, Sonechkin DM, Holmgren K, Datsenko NM, Karlén W (2005) Highly variable Northern Hemisphere temperatures reconstructed from low- and high-resolution proxy data. Nature 433:613-617

Sato T (2009) Influences of subtropical jet and Tibetan Plateau on precipitation pattern in Asia: insights from regional climate modeling. Quaternary Int 194:148-158

Shanahan TM, Overpeck JT, Anchukaitis KJ, Beck JW and others (2009) Atlantic forcing of persistent drought in West Africa. Science 324:377-380

Sheppard P, Tarasov P, Graumlich L, Heussner K, Wagner M, Osterle H, Thompson L (2004) Annual precipitation since $515 \mathrm{BC}$ reconstructed from living and fossil juniper growth of northeastern Qinghai Province, China. Clim Dyn 23: 869-881

Stige LC, Chan KS, Zhang Z, Frank D, Stenseth NC (2007) Thousand-year-long Chinese time series reveals climatic forcing of decadal locust dynamics. Proc Natl Acad Sci USA 104:16188-16193

Su M, Wang H (2007) Relationship and its instability of ENSO: Chinese variations in droughts and wet spells. Sci China D Earth Sci 50:145-152

> Sung MK, Kwon WT, Baek HJ, Boo KO, Lim GH, Kug JS (2006) A possible impact of the North Atlantic Oscillation on the East Asian summer monsoon precipitation. Geophys Res Lett 33:L21713 doi:10.1029/2006GL027253 
Tabachnick BG, Fidell LS (2007) Using multivariate statistics. Pearson/Allyn \& Bacon, Boston, MA

Tan L, Cai Y, Yi L, An Z, Ai L (2008) Precipitation variations of Longxi, northeast margin of Tibetan Plateau since AD 960 and their relationship with solar activity. Clim Past 4:19-28

Trouet V, Esper J, Graham NE, Baker A, Scourse JD, Frank DC (2009) Persistent positive North Atlantic Oscillation mode dominated the medieval climate anomaly. Science $324: 78-80$

Turchin P (2005) Dynamical feedbacks between population growth and sociopolitical instability in agrarian states. Struct Dyn 1:19

> Verschuren D, Laird KR, Cumming BF (2000) Rainfall and drought in equatorial East Africa during the past 1100 years. Nature 403:410-414

> Vicente-Serrano SM, López-Moreno JI (2006) The influence of atmospheric circulation at different spatial scales on winter drought variability through a semi-arid climatic gradient in northeast Spain. Int J Climatol 26:1427-1453

- Wang G, Cheng G (2000) The characteristics of water resources and the changes of the hydrological process and environment in the arid zone of northwest China. Environ Geol (Berl) 39:783-790

Wang B, Wu R, Fu X (2000) Pacific-East Asian teleconnection: How does ENSO affect East Asian climate? J Clim 13: $1517-1536$

Wang N, Xie Y, Xue X (2002) Jin liangqian nian lai rennei huodong dui woguo xibu shengtai huangjing bianhua de yingxiang. Collect Essays Chin Hist Geogr 17:12-19

Wei F, Xie Y, Mann ME (2008) Probabilistic trend of anomalous summer rainfall in Beijing: role of interdecadal variability. J Geophys Res 113:D20106 doi:10.1029/2008JD010111

Wisner B, Blaikie P, Cannon T, Davis I (2004) At risk: natural hazards, people's vulnerability and disasters. Routledge, London

Xie Y, Fu Q (2004) Analysis of famines caused by heavy floods and droughts in China. Nature Sci 2:25-32

Xin X, Yu R, Zhou T, Wang B (2006) Drought in late spring of south China in recent decades. J Clim 19:3197-3206

Editorial responsibility: Mauricio Lima,

Santiago, Chile
Yang Z (2008) The research on natural disaster and modern northwest society: modern northwest natural disaster and population migration. Northwest Popul 29:38-43

Yang B, Braeuning A, Johnson KR, Shi Y (2002) General characteristics of temperature variation in China during the last two millennia. Geophys Res Lett 29:1324

> Yang B, Wang J, Braeuning A, Dong Z, Esper J (2009) Late Holocene climatic and environmental changes in arid central Asia. Quat Int 194:68-78

Yin Y, Xu Y, Chen Y (2009) Relationship between flood/drought disasters and ENSO from 1857 to 2003 in the Taihu Lake basin, China. Quat Int doi:10.1016/j.quaint.2008.12.016

Yu Y, Yang T, Li J, Liu J and others (2006) Millennial-scale Holocene climate variability in the NW China drylands and links to the tropical Pacific and the North Atlantic. Palaeogeogr Palaeoclimatol Palaeoecol 233:149-162

Yuan L (1994) Xibei zaihuang shi. Gansu Renmin Chubanshe, Lanzhou

Zhang Z, Li D (1999) A possible relationship between outbreaks of the oriental migratory locust (Locusta migratoria manilensis Meyen) in China and the El Niño episodes. Ecol Res 14:267-270

Z Zhang P, Cheng H, Edwards RL, Chen F and others (2008a) A test of climate, sun, and culture relationships from an 1810-year Chinese cave record. Science 322:940-942

Zhang Q, Gemmer M, Chen J (2008b) Climate changes and flood/drought risk in the Yangtze Delta, China, during the past millennium. Quat Int 176-177:62-69

> Zhang Z, Cazelles B, Tian H, Stige LC, Bräuning A, Stenseth NC (2009) Periodic temperature-associated drought/flood drives locust plagues in China. Proc R Soc Lond B 276: $823-831$

Zhao Z (2006) Agricultural reclamation policy and environmental changes in the northwest China during the Qing dynasty. Front Hist China 1:276-291

Zhao W, Xie S (1988) Zhongguo renkou shi. Renmin Chubanshe, Beijing

Zhu E (1999) Zhongguo dongya feihuang fasheng yu zhili. Zhongguo Nongye Chubanshe, Beijing

Submitted: August 31, 2009; Accepted: March 16, 2010

Proofs received from author(s): April 21, 2010 